\title{
Accounting
}

\section{The impact of economic value added (EVA) adoption on stock performance}

\author{
Amer Al Shishany ${ }^{a *}$, Ahmed Al-Omush ${ }^{b}$ and Cherif Guermat ${ }^{c}$
}

${ }^{a}$ Department of Business Administration, Faculty of Economics and Administrative Science, The Hashemite University/Zarqa, Jordan

${ }^{b}$ Department of Accounting, Faculty of Economics and Administrative Science, The Hashemite University/Zarqa, Jordan ${ }^{c}$ Professor of Empirical Finance, FBL - Accounting, Economics and Finance, University of the West of England, Bristol, UK

\section{H R O N I C L E}

\section{Article history:}

Received May 102020

Received in revised format May

152020

Accepted June 262020

Available online

June 262020

Keywords:

Event study

EVA

Stock performance

Compensation

CAR

$B H A R$

\section{A B S T R A C T}

The adoption of EVA as a compensation and management plan, generally, impacts positively the performance of companies adopting this method. However, this paper examines whether the adoption of the EVA framework enhances the firm's performance and gauge the long-term effects of such an adoption on the firm's value. It also assesses whether the market reacts to the announcement of the adoption of EVA as a compensation system. Moreover, the paper fills this gap in research literature by showing whether or not EVA adoption leads to a significant increase in firm value as reflected by its market prices on the long run. Growing evidence in research indicates that the stock market does not incorporate all firm information into the stock price quickly and completely. Therefore, the critique that contemporaneous association between price and EVA does not reflect reality is likely to be correct. However, this paper takes a different action. The basic contention is that although prices adjust slowly to information, long horizons are sufficiently long for markets to incorporate almost all relevant information into prices. The study sample consists of 89 US firms adopted EVA as a compensation system. It compares the performance of adopting firms to that of selected matching firms and to the market indexes, particularly, the S\&P500 portfolio. Then it uses two common aggregating methods to test the event of adopting EVA by different US firms namely the CAR and BHAR methods. The results obtained, however, showed a slight improvement in the performance of companies adopting EVA within five years from the date of adoption.

\section{Introduction}

It is generally accepted that the normative role of the executive manager is to maximize firm value (Wallace, 1997; Malmi \& Ikaheimo, 2003). But a long-standing problem for the owners of the firm has been that a fiduciary role by the manager does not occur naturally. There must be some form of compensation design that induces the required management behaviour. Any design, in turn, requires a measure of firm performance. How do we know that a manager has increased firm value? One traditional measure is Share Price (Jensen \& Murphy, 1990). However, Share Price depends on factors beyond management control (Sloan, 1993; Lambert, 1993). Furthermore, in the short run, maximising share price might not always be aligned with maximising the firm's intrinsic value (Mramor \& Valentincic, 2001). Other traditional measures used in assessing managers' performance include earnings, return on assets, return on investment and other cash flow measures. However, there are wellknown problems with these measures (subjectivity and ease of manipulation). The search was therefore on for new performance

* Corresponding author. Tel: +96253903333/3340

E-mail address: asalsha@hu.edu.jo (A. Al Shishany) 
measures that would improve on the traditional accounting-based measures. Practitioners obliged. Consulting firms began marketing their own value based performance measures (Myers, 1997). The most prominent of these was Stern and Stewart's Economic Value Added (EVA) (Stern \& Stewart, 1991). Stewart (1994, p.75) proclaimed that "EVA stands well out from the crowd as the single best measure of value creation on a continuous basis", and that "EVA is almost $50 \%$ better than its closest accounting-based competitor (i.e. earnings), in explaining changes in shareholder wealth". However, although these measures were driven by practitioners, value-based ideas had been known for more than a century before they were marketed by consulting firms. Wallace (1997) states that Alfred Marshall mentioned the residual income concept in 1890. This same measure was also discussed by Canning (1929) and Preinreich (1937) who referred to it as excess earnings, while Edey (1957) referred to it as super-profits. The basic idea of this measure is that unless a business "returns a profit that is greater than its cost of capital, it does not create wealth; it destroys it." (Drucker, 1995, p.59). Previous research has examined whether the adoption of EVA's incentive compensation plan has any impact on managers' decision making (Wallace, 1997; Kleiman, 1999; Hogan \& Lewis, 2005). All of this empirical research has the common assumption that the adoption of the EVA compensation system will rationalize a firm's investment decision and will lead to using the existing assets more efficiently to generate more residual income and, hence, to maximize shareholders' wealth, as well. These studies tested EVA adoption effects for up to five years after adoption. A major limitation in the existing literature is that the focus was on changes in the manager's behaviour as reflected by accounting fundamentals. Adoption of EVA is supposed to increase asset dispositions, repurchases, and dividends, while at the same time decrease new investments and accounts payable. However, if adopting EVA really led to optimal management decisions, the above effects may be necessarily observed. For example, a firm could have under-invested prior to adopting EVA. An optimal behaviour would see an increase in new investments rather than a decrease. Thus, even if EVA did induce the management to optimise firm value, the optimal change in the accounting variables may not always be in the same direction. This is probably why the various studies that studied the effect of EVA adoption have found different and often conflicting results (Wallace, 1997; Kleiman, 1999; Cahan et al., 2002; Hogan \& Lewis, 2005; Balachandran, 2006). In short, while existing evidence points to a change in management decision, there is no evidence that adopting EVA increases value.

Apart from management-behaviour effect studies mentioned above, the other line of enquiry focused on value relevance (Biddle et al., 1997; Lehn \& Makhija, 1997). The general finding is that EVA actually has poorer explanatory power than other traditional performance metrics such as earnings. Surprisingly, we know of no study that has tested directly the value effect of EVA adoption. The aim of this paper is to fill this gap in the literature by showing whether or not EVA adoption leads to a significant increase in firm value as reflected by its market prices in the long run. While we agree that in the short run, the market might be subject to a number of behavioural and informational inefficiencies. There is growing evidence that the stock market does not incorporate all firm information into the stock price quickly and completely. Therefore, the critique that contemporaneous association between price and EVA does not reflect reality is likely to be correct. However, we take a different take. Our basic contention is that although prices adjust slowly to information, long horizons are sufficiently long for markets to incorporate almost all relevant information into prices. In other words, our basic assumption is that markets are efficient in the long run (Fama, 1998, JFE, 49, 283-306). This paper will therefore examine whether the adoption of the EVA framework enhances the firm's performance and to gauge the long-term effects of such an adoption on the firm's value. It also assesses whether the market reacts to the announcement of the adoption of EVA as a compensation system. The event study methodology initially introduced by Fama et al. (1969) will be used to assess the impact of EVA's adoption on a firm's performance. The adoption the trademarked EVA performance measure grew rapidly during the 1990s in the USA, but does not seem to be popular in Europe. For example, in the UK only four companies have reported the EVA as a performance and management tool. ${ }^{1}$

The structure of this paper is organized as follows. Section 2 summarises the main results of the previous studies that have investigated the impact of EVA adoption on a firm's performance. Sections 3 and 4 describe the sample and the methodology respectively. Section 5 discusses the empirical results obtained and finally section 6 summarises the main conclusions.

\section{Previous studies}

To our knowledge, there are only two studies on stock price performance following adoption of EVA as a compensation measure. The first study focuses on the short-term market reaction to EVA adoption. Tortella \& Brusco (2003) used a sample of 65 EVA adopter firms and compared the daily abnormal return of adopting firms to that of two index portfolios. They used a window of 30 days prior to the adoption and 100 days post the adoption. Their results indicate that the daily cumulative average abnormal return is insignificant throughout the post event window. They conclude that the market does not react to the adoption of EVA in the short run. Ferguson et al. (2005), on the other hand, do a long-term event study on EVA adoption. They use a list of 65 EVA adopter firms provided by Stern Stewart \& Co. However, our study differs in many respects. First, we use a larger sample of 89 firms, which is likely to improve the statistical credence of our empirical results. Moreover, our sample goes to 2001 while their sample ends in 1998. Second, they rely exclusively on the cumulative abnormal return (CAR) concept in their analysis. Abnormal returns have their own shortcomings and have been criticised severely for prompting certain biases

\footnotetext{
${ }^{1}$ These companies are Tate \& Lyle, GSK, Hanson (now Heidelberg) and Diageo. Source: Stern Stewart Ltd. London Branch dated March 15, 2012.
} 
(Barber and Lyon, 1996, 1997; Fama, 1998). In this study we use both CAR and the buy-and-hold abnormal return (BHAR) concept. BHAR is well known for its ability to represent investor's experience (Mitchell and Stafford, 2000). Third, they use market model to estimate predicted or expected returns. This may suffer from the bad model problem (Fama, 1998). In this study we use matching control firms to calculate abnormal return or abnormal buy and hold return. The use of matching control firm is less likely to suffer from the bad model problem (Stuart, 2010). The other line of enquiry that is closely related to our objectives is the one that focused on the effect of EVA adoption on internal firm decisions such as financing and operating decisions. This kind of research was initiated by the seminal paper of Wallace (1997), and was then followed by several studies over the following decade (Kleiman, 1999; Cahan et al., 2002; Hogan \& Lewis, 2005; Balachandran, 2006). The underlying assumption in the above studies is that firms adopting EVA will create the ability to enhance their profitability and maximize shareholder's wealth. This can be achieved by increasing a firm's ability to generate a large residual income and encourage managers to invest in those projects that can earn more than the cost of the capital invested. Furthermore, EVA's proponents claim that the adoption of the EVA framework will affect the manager's behaviour and lead to the best alignment of management interests with those of the shareholders (Stewart, 1991; Wallace, 1997). The existing empirical studies on the adoption of residual income-based performance incentives have found mixed results. Wallace's (1997) study initiated this line of enquiry by addressing the changes in a number of firm decisions following the adoption of residual income or EVA measures. Wallace (1997) was been replicated by a number of scholars such as Kleiman (1999), Hogan \& Lewis (2005) and Balachandran (2006). Wallace (1997) compared a group of forty companies adopting residual income or EVA as a compensation plan with the same number of control firms to examine whether the adoption of these measures, impacted the investing decisions, financing decisions, operating decisions and shareholder wealth. Kleiman (1999) extended Wallace's sample to 71 firms, but focus exclusively on firms adopting EVA as an incentive compensation system. Kleiman (1999) found that EVA adoption led to higher stock return performance. Inconsistent with Wallace (1997), Kleiman's (1999) results do not show any capital expenditure decline following adoption of EVA. On the other hand, he reports that EVA-adopting companies significantly increase their financial leverage, extend share repurchases, and enhance both operating margins and operating profits before depreciation. Hogan and Lewis (2005) used a sample of 108 firms that chose to adopt the economic profit plans (EPPs) as incentive compensation systems between 1983 and 1996 to examine whether the adoption would affect these firms' operating, organizational, financial and compensation characteristics. The findings of Hogan \& Lewis (2005) reveal that EPP adopter firms in general show a significant enhancement in operating performance relative to their past performance (pre-adoption period). In addition, they show a significant difference in investment behaviour, operating performance and value creation. This result is consistent with the notion that an EPP-based compensation system encourages managers to choose profitable projects that ultimately maximize shareholders' wealth. However, they found significant differences between anticipated adopter firms and surprise adopter firms. The improved performance referred to above appears to have been driven mostly by anticipated adopters, which points to potential self-selection bias. The above studies looked at the adoption of EVA (or residual income) plans regardless of what measure was used before adoption. Balachandran (2006) argues that the original plan is important as adoption of EVA or residual income might actually increase or decrease investment pattern, even though the delivery of residual income would increase in both cases. This implies that firm value maximisation does not necessarily entail an increase or decrease in investments. Balachandran (2006) used a sample of 181 firms that adopted the residual income (RI)-based compensation incentive. These firms fell into two main categories: those which previously adopted earnings as a compensation plan and those which previously adopted return on investment (ROI) based compensation plan. He focused on two outputs, namely, the change in RI and the change in investment. His results show strong support for the view that RI-adopting firms do actually deliver higher RI after adoption. However, the results also show no significant change in investment pattern.

\section{Sample}

Our sample consists of 89 US firms that have adopted EVA as a compensation system. We follow Wallace (1997) and Kleiman (1999) and define the end of the first year of the company announcing its adoption of EVA as the event date $(t=0)$. The identity of adopting firms was found as follows. We began with Wallace's (1997) 23 firms that adopted the EVA compensation plan. We then added the firms used by Kleiman (1999). This increased the number to 71 firms. Subsequently, we searched for additional firms using various databases where the EVA adoption was specifically mentioned. These comprise the Stern Stewart \& Co. brochure, Lexis-Nexis, Proxy Statement, 10-Q report and Wall Street Journal. The majority of firms which adopted EVA have disclosed such information in their official release. We identified a total of 101 adopting firms in the period 1987- 2001. However, 12 EVA adopters were excluded because of lack of price/return and accounting data. Our final sample contains 89 EVA adopters on NASDAQ, NYSE and American Stock Exchange Markets. Because we use both the market model and control firm approaches to estimate abnormal performance, each of the adopter firm was matched with a benchmark firm. We follow Wallace (1997) who uses the Standard Industrial Classification (SIC) to match the adopter and benchmark firms. We used three criteria for matching firm selection. First, the company should have the same 4-digits SIC code (Same industry sector). If we do not find a firm with 4 digits match, we choose the best match with a 3-digits SIC code. If there are several firms with the same 4 or 3 digit SIC code, then we select the nearest size using a combination of the total asset and number of outstanding common shares in the year prior to the year of adoption to match adopters and control firms. Finally, if a benchmark firm does not have sufficient monthly data during the event period, we select the next best benchmark in terms of SIC code and size. 
The price and return data of both adopting and control firms were collected from CRSP database. Appendix 1 provides a breakdown of firms adopting EVA and the year of adoption, the main control firms and the SIC code respectively.

Table 1

EVA Adoption Years of Sample Companies $(1987-2001)$

\begin{tabular}{|c|c|c|}
\hline Year & Number of Companies & Percentage \\
\hline 1987 & 1 & $1.12 \%$ \\
\hline 1988 & 1 & $1.12 \%$ \\
\hline 1989 & 1 & $1.12 \%$ \\
\hline 1990 & 2 & $2.25 \%$ \\
\hline 1991 & 1 & $1.12 \%$ \\
\hline 1992 & 4 & $4.49 \%$ \\
\hline 1993 & 10 & $11.24 \%$ \\
\hline 1994 & 18 & $20.22 \%$ \\
\hline 1995 & 13 & $14.61 \%$ \\
\hline 1996 & 17 & $19.10 \%$ \\
\hline 1997 & 8 & $8.99 \%$ \\
\hline 1998 & 7 & $7.87 \%$ \\
\hline 1999 & 4 & $4.49 \%$ \\
\hline 2000 & 1 & $1.12 \%$ \\
\hline 2001 & 1 & $1.12 \%$ \\
\hline Total & 89 & $100 \%$ \\
\hline
\end{tabular}

\section{Method}

Defenders of Economic Value Added (EVA) claim that it helps to enhance the investment activity that leads to a notable market reaction (Stewart, 1991). The object this paper is to examine whether the adoption of EVA has the predicted positive effect on firm value. If EVA does indeed have such a positive effect on value, then the market should identify this change in the firm and react positively at least in the long run. If that is the case, then we should observe significant abnormal market performance (as measured by abnormal returns or abnormal buy and hold returns) either immediately (if the effect is true and the market is efficient), or slowly (if the market only absorbs information slowly). To test this claim we use an event study approach. Some event studies research has been dedicated to testing market efficiency. However, most of the event studies have been used to assess the impact of some events on some measure of the firm or investor wealth. Many studies have discussed and examined the long-term financial performances after the occurrences of certain events such as the IPO, mergers and acquisitions and the most popular event, cash dividends. One common feature of these studies is that of the classical event approach, which fully intended to investigate very short-term events. In a string of seminal papers, Barber \& Lyon (1996, 1997) and Lyon, Barber, \& Tsai (1999), revealed that the standard classical event study framework can lead to many partialities when applied to the measurement of long-term abnormal performances and recommended further study for such long-term events analysis. Further, Fama (1998) raised two important key issues regarding measuring long-term abnormal returns: first, the model's ability to correct for risk when estimating abnormal returns is quite low and second, the estimation of abnormal returns is probably subject to a range of statistical biases. Thus, to avoid estimation and bad model problems, we use direct benchmarking using both the market index and a matched control firm. The event window is set to 60 months before and after the adoption date. In the literature there are two methods to test the events and detect a long-run abnormal stock return: the cumulative abnormal return (hereafter, CAR) and the Buy and Hold Abnormal Return (hereafter, BHAR). The main difference between CAR and BHAR is mainly attributed to the compounding of the monthly return; while BHAR incorporates the effect of compounding CAR does not (Barber \& Lyon, 1997). Regardless of the methodology used to measure the performance of the EVA adopter, CAR or BHAR, we need to measure the abnormal return. The abnormal return is the difference between the actual return and the benchmark return of a security. Events in the theory of finance can usually be classified as information that has not already been contained in the share's market price. Let $R_{i t}^{a}$ be the return on adopter (event) firm $i$, and $R_{i t}^{b}$ be the return on a benchmark stock. When we use the marked index as benchmark, then we simply set $R_{i t}^{b}=R_{m t}$, where $R_{m t}$ is the return on the market portfolio. Accordingly abnormal returns are given by

$$
A R_{i t}=R_{i t}-R_{i t}^{b}
$$

The average abnormal return $\left(A A R_{t}\right)$ during month $s$ can be defined as: 


$$
\begin{aligned}
& \text { A. Al Shishany et al. /Accounting 6 (2020) } \\
& \qquad A A R_{t}=\frac{1}{N_{t}} \sum_{i=1}^{N_{t}} A R_{i t}
\end{aligned}
$$

where $A R_{i t}$ is the abnormal return estimator for security $i$ and $N_{t}$ is the number of the companies in the sample during month $t$. The cumulative average abnormal return in the window of $\left(s_{1}, s_{2}\right)$ is:

$$
C A R_{s_{1} s_{2}}=\sum_{t=s_{1}}^{s_{2}} A A R_{t}
$$

The second method used to calculate the abnormal return is buy and hold abnormal return (BHAR) which is defined as the compound returns on the event firm less the compound return on a control firm / reference portfolio- that is BHAR:

$$
B H A R_{i \tau}=\left[\prod_{t=1}^{\tau}\left(1+R_{i t}^{a}\right)\right]-\left[\prod_{t=1}^{\tau}\left(1+R_{i t}^{b}\right)\right]
$$

where $\tau$ is the period of investment in months, $R_{i t}^{a}$ is the return on the event firm (adopter firm) $i$ in month $t . R_{i t}^{b}$ is the benchmark returns. As our main method to test the event is BHAR it is more efficient to highlight the skewness problem inherited within the process of making inferences using BHAR. This problem is reported in Barber and Lyon (1997). In order to conduct the significance test in event time using BHAR, the following conventional $t$-statistic is used based on cross sectional data:

$$
t_{\tau}=\frac{\bar{B} \bar{H} \bar{A} \bar{R}_{\tau}}{\sigma_{i \tau} / \sqrt{N}}
$$

where $\bar{B} \overline{H A} \bar{R}_{\tau}$ is the sample mean, $\sigma_{i \tau}$ is the standard deviation, and $N$ is the number of EVA adopter firms. The compound nature of BHAR induces skewness in the above statistic. To circumvent this problem, we use a bootstrap correction, originally proposed by Johnson (1978):

$$
S K a d j-t_{\tau}=\sqrt{N}\left(S+\frac{1}{3} \hat{\gamma} S^{2}+\frac{1}{6 N} \hat{\gamma}\right)
$$

Where $\hat{\gamma}$ is the coefficient of skewness, and $S \equiv \bar{B} \bar{H} \bar{A} \bar{R}_{\tau} / \sigma_{i \tau}$. This adjustment was recommended by Lyon et al. (1999) to correct for potential skewness in BHAR returns. Kothari \& Warner (1997) state that, drawing statistical inferences from a bootstrap approach is likely to be a better technique for statistical testing of long-term stock abnormal performance. However, while standard bootstrapping on the skewness-adjusted t-statistic does indeed address skewness concerns, it does not address the question of heteroscedasticity. In our case adoption takes place over a number of years. During these years there are periods where the market is highly volatile and others where it is relatively calm. Returns and, hence, abnormal returns, drawn from different periods are likely to have been drawn from distributions having different volatilities. The standard bootstrap does not correct for heteroscedasticity. The wild bootstrap, on the other hand, is designed to account for heteroscedasticity. Despite its properties, the wild bootstrap has unfortunately seen very little use in empirical finance. The standard bootstrap draws samples (with replacement) from the set of estimated variable. In our case, we draw samples $\hat{\varepsilon}_{i}^{*}$ from the residual series $\hat{\varepsilon}_{i}=B H A R-\bar{B} \overline{H A} \bar{R}$ ). With the wild bootstrap the bootstrap samples $\hat{\varepsilon}_{i}^{*}$ are the product of the original residuals with an independent random variable, $\eta_{i}$, with zero mean and unit variance (that is, $\hat{\varepsilon}_{i}^{*}=\eta_{i} \hat{\varepsilon}_{i}$ ). The bootstrap variance is guaranteed to be the same as that of the parent distribution. For example, for the standard normal case we have

$$
E\left(\hat{\varepsilon}_{i}^{*}\right)=E\left(\eta_{i}\right) E\left(\hat{\varepsilon}_{i}\right)=0 \text { And } V\left(\hat{\varepsilon}_{i}^{*}\right)=V\left(\eta_{i}\right) V\left(\hat{\varepsilon}_{i}\right)=V\left(\hat{\varepsilon}_{i}\right)
$$

However, the normal distribution is not appropriate when the data is skewed since $E\left(\eta_{i}^{3}\right)=0$. Liu (1988) \& Mammen (1993) suggest ways of obtaining $E\left(\eta_{i}^{3}\right)=1$ but their sampling schemes do not preserve the kurtosis of the parent distribution. An alternative sampling scheme that preserves the mean, variance and kurtosis $\left(E\left(\eta_{i}\right)=0\right.$, and $\left.E\left(\eta_{i}^{2}\right)=E\left(\eta_{i}^{4}\right)=1\right)$ but not skewness $\left(E\left(\eta_{i}^{3}\right)=0\right.$ ) was proposed by Davidson et al. (2007), namely 


$$
\eta_{i}=\left\{\begin{array}{ccc}
1 & \text { with probability } & p=\frac{1}{2} \\
-1 & \text { with probability } & 1-p
\end{array}\right.
$$

This latter scheme is preferred since we use the skewness adjusted t-statistic which corrects for skewness, and thus skewness is not an issue (with the adjustment of Johnson (1978) the parent distribution of the adjusted statistic is expected to be symmetric).

A further serious problem that we confront both in the EVA adopter sample and the control firm sample is that of firms that delist within the event period. Delisting can result from acquisition, bankruptcy or going private. Liu \& Strong (2006) replace delisted firm returns by either zero or the risk-free rate. They find similar results in both cases. Lyon, Barber \& Tsai (1999) and Mitchell \& Stafford (2000, p.298) replace all de-listed firms with the benchmark return. This has the potential to create an upward bias in the estimated BHAR returns, since some of these de-listings are bankruptcies. However, for the purpose of our study we use the following rules. If an observation is missing within a valid set of observations, we set the return equal to zero. If the de-listings are due to bankruptcy, we replace the missing return by -1. Finally, if the delisting is due to a value preserving event such as a merger, we replace the return by the benchmark return. We use CRSP description as a distinguishing feature of the delisted firms. The Delisting Code is a 3-digit integer code. It either (1) indicates that a security is still trading or (2) provides a specific reason for delisting. All coded de-listings are categorized by the first digit of the delisting code. The second and third digits of the delisting codes provide further details of delisting events. Additional delisting codes, specific to various delisting categories, have been created to indicate when an issue is closed to further research, or if the issue is pending further research. The most important codes are 241,231, 233, 331, 251, 552 and 574. These categories of delisting are most likely to be stocks that are either worthless or some distance from providing shareholders with any terminal value, and consequently we treat these cases as if investors lost all their investment.

\section{Results}

\subsection{Cumulative Abnormal Return Results}

We begin by discussing cumulative abnormal returns. All results are displayed as follows. The average CAR, the standard tstatistics, the skewness adjusted t-statistic with its bootstrapped confidence intervals, the skewness and kurtosis of each set of cumulative abnormal returns is shown for selected months. The statistics are shown in a brief table that shows the $1^{\text {st }}, 10^{\text {th }}, 20^{\text {th }}$ and up to the $60^{\text {th }}$ month. Whenever the standard t-statistic is above 1.96, the results are also shown. The full 60 months' version of the table is provided in the appendix. To complete the picture, we provide a graphic summary of CAR, the skewness adjusted t-statistic and the $1 \%$ and $99 \%$ quantiles obtained from the wild bootstrap. Table 2 reveals an interesting story about the overall performance, the cumulative abnormal return (CAR) for the 10 years after the adoption date. Throughout the 5-year post-event period, most of the CARs appear to be positive but insignificant except for the months 27, 28, 29 and 30 which are in the third year after EVA adoption. During these months the mean CARs are at their highest levels and are significant. However, following these months, we find that CARs start to decline and then rebound up again around month 40. After that we see that CARs decrease and fall into negative territories. Especially in the last 4 months in year 5 this negative trend is quite visible indicating that EVA adopters underperform their matched non-EVA firms. Figure 1 depicts AR against CAR based on matching firms' benchmarking.

Table 2

Matching Firm Based Cumulative Abnormal Returns (CAR)

\begin{tabular}{ccccccccc}
\hline Month & $\mathrm{N}$ & Mean & t-stat & Adj-SK-t & F1-1\%b & F1-99\%b & Skewness & Kurtosis \\
\hline 1 & 87 & 0.024 & 1.599 & 1.719 & -2.562 & 2.358 & 1.104 & 3.605 \\
$\mathbf{1 0}$ & 87 & -0.005 & -0.145 & -0.151 & -2.26 & 2.423 & -0.289 & 0.600 \\
20 & 87 & 0.079 & 1.454 & 1.521 & -2.601 & 2.327 & 0.721 & 2.139 \\
27 & 87 & $\mathbf{0 . 1 4 6}$ & $\mathbf{2 . 1 5 7}$ & 2.365 & -2.568 & 2.653 & 1.126 & 4.581 \\
28 & 87 & $\mathbf{0 . 1 4 7}$ & $\mathbf{2 . 0 7 0}$ & 2.315 & -2.863 & 2.661 & 1.433 & 8.619 \\
29 & 87 & $\mathbf{0 . 1 5 2}$ & $\mathbf{2 . 1 0 4}$ & 2.360 & -2.831 & 2.758 & 1.451 & 8.893 \\
30 & 87 & $\mathbf{0 . 1 4 0}$ & $\mathbf{1 . 9 8 4}$ & 2.192 & -2.562 & 2.563 & 1.312 \\
40 & 87 & 0.122 & 1.424 & 1.467 & -2.579 & 2.536 & 0.473 & 3.915 \\
$\mathbf{5 0}$ & 85 & -0.017 & -0.140 & -0.136 & -2.332 & 2.452 & 0.233 & 3.597 \\
$\mathbf{6 0}$ & 82 & -0.032 & -0.245 & -0.254 & -2.404 & 2.480 & -0.424 & 2.574 \\
\hline
\end{tabular}



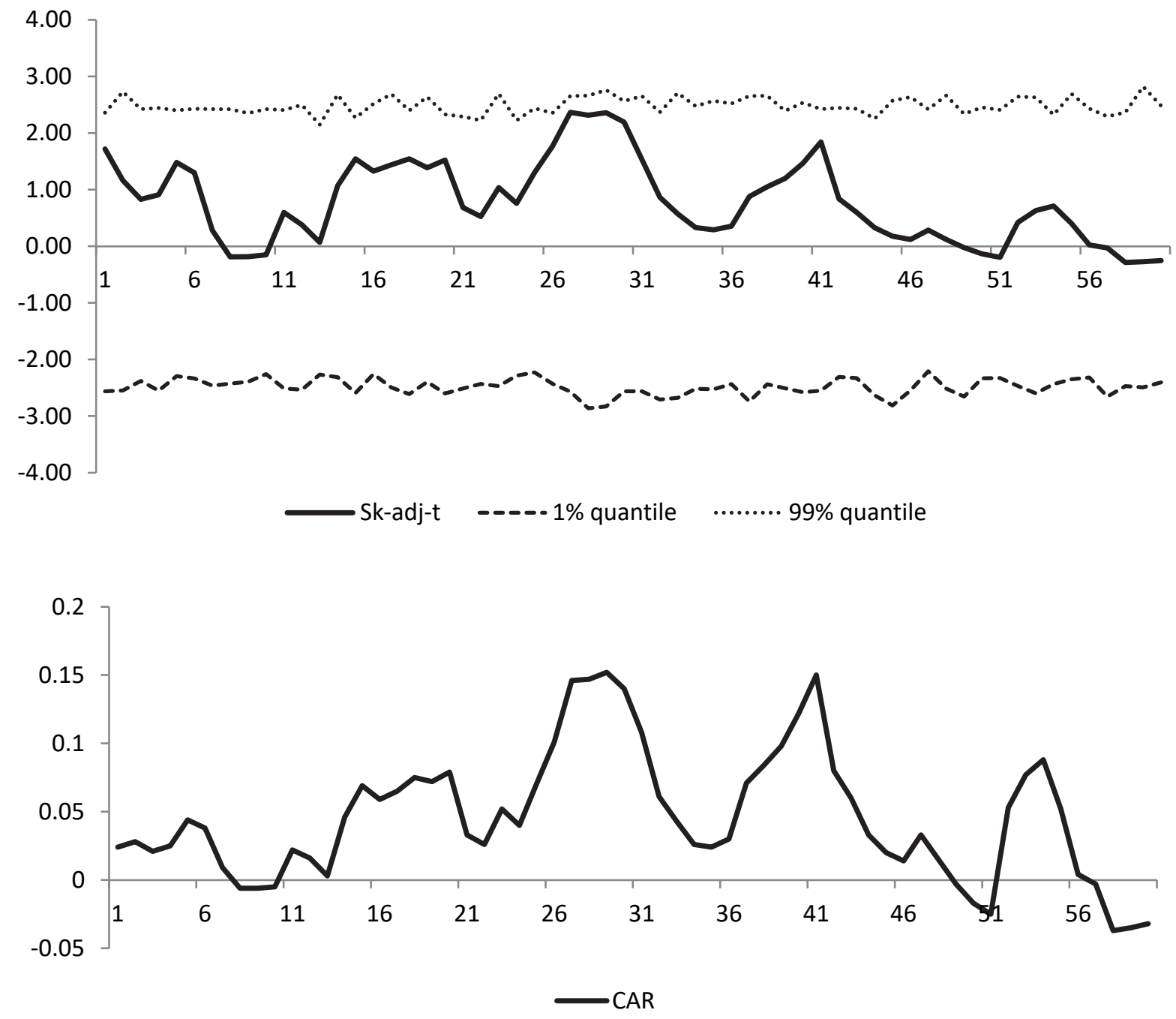

Fig. 1. Average CAR results based on Matching Firm Abnormal Returns

Table 3 shows CARs based on market benchmarks (S\&P 500), In nearly all months, adopter firms outperform the market with small variances which does not increase in the best of cases more than $8.5 \%$ at month 20 and this is the only significant month of the 5 year post-event period. The mean return based on CAR is positive for most months except for months 34,35 and 36 , which give negative CAR. All the CAR returns are skewed and leptokurtic, this might be attributed to the compounding process inherited in CAR calculations. However, the simple CAR based on matching firms and market benchmarking shows similar dynamics- the scale of the suggested outperformance is not the same. Firstly, the CAR based on matching firms is about twice as large as the CAR based on the market benchmark in the positive cases. Secondly, CAR based on benchmarking is only negative between months 34 and 36. This is followed by an apparent upward trend (Figure 2).

\section{Table 3}

Market Benchmark Based Cumulative Abnormal Return

\begin{tabular}{|c|c|c|c|c|c|c|c|c|}
\hline Month & $\mathbf{N}$ & Mean & t-stat & Adj-SK-t & F1-1\%b & F1-99\%b & Skewness & Kurtosis \\
\hline 1 & 87 & 0.003 & 0.222 & 0.229 & -2.519 & 2.456 & 0.356 & 1.531 \\
\hline 10 & 87 & 0.013 & 0.479 & 0.507 & -2.711 & 2.445 & 1.097 & 2.635 \\
\hline 20 & 87 & 0.085 & 1.848 & 2.091 & -2.477 & 2.551 & 1.737 & 5.677 \\
\hline 30 & 87 & 0.066 & 0.929 & 1.004 & -2.404 & 2.59 & 1.535 & 5.988 \\
\hline 40 & 87 & 0.020 & 0.252 & 0.279 & -2.632 & 2.659 & 1.336 & 3.738 \\
\hline 50 & 85 & 0.029 & 0.262 & 0.289 & -2.346 & 2.313 & 1.295 & 3.024 \\
\hline 60 & 82 & 0.013 & 0.108 & 0.119 & -2.604 & 2.396 & 0.598 & 2.310 \\
\hline
\end{tabular}



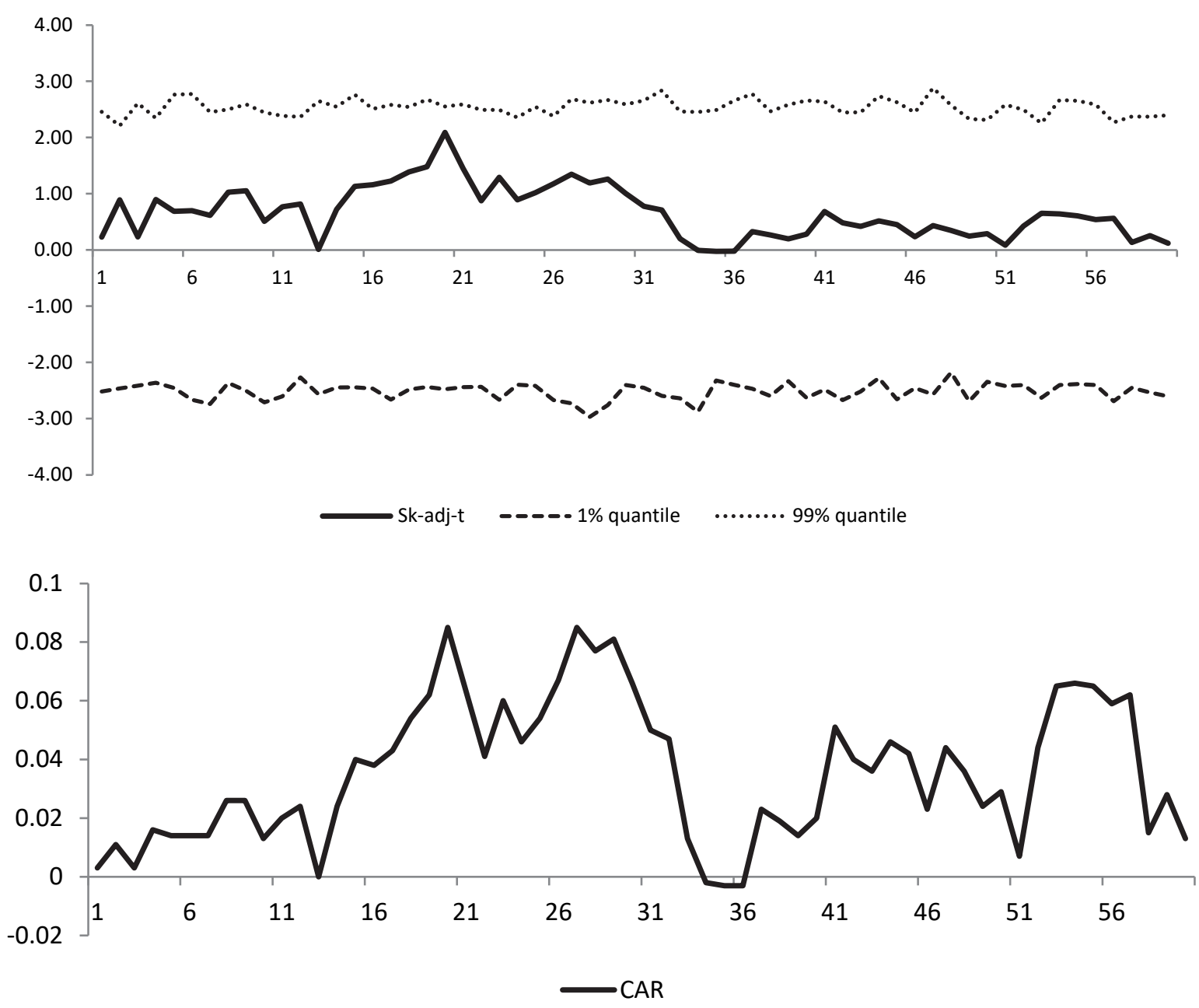

Fig. 2. Average CAR Results Based on Market Index Abnormal Returns

\subsection{Buy and Hold Return Results}

Our first results regarding the BHAR, presented in Table 4, show the BHAR derived using firm benchmark. The BHAR increases from an insignificant $+1.0 \%$ after 9 months to a significant $36.4 \%$ after 27 months, becoming insignificant thereafter and continuing to increase to $37.4 \%$ after 41 months, $40.2 \%$ after 45 months, and then starts to decline to reach the lowest return of $4.3 \%$ after 59 months. All returns are skewed and leptokurtic. It is worth noting that the adopter's buy and hold return (BHAR) itself is highly skewed and leptokurtic throughout the period and that the matching firm is also skewed and leptokurtic, but to a lesser extent.

Table 4

Summary Statistic for BHAR Matching firms

\begin{tabular}{|c|c|c|c|c|c|c|c|c|}
\hline Month & $\mathbf{N}$ & Mean & t-stat & $\begin{array}{c}\text { Adjusted Sk. } \\
\text { t-stat }\end{array}$ & $\begin{array}{c}1 \% \text { bootstrap } \\
\text { quantile }\end{array}$ & $\begin{array}{c}99 \% \text { bootstrap } \\
\text { quantile }\end{array}$ & Skewness & Kurtosis \\
\hline 1 & 87 & 0.024 & 1.599 & 1.719 & -2.487 & 2.533 & 1.104 & 3.605 \\
\hline 10 & 87 & 0.014 & 0.335 & 0.342 & -2.415 & 2.25 & 0.308 & 2.038 \\
\hline 20 & 87 & 0.152 & 1.689 & 2.056 & -2.587 & 2.666 & 3.060 & 16.422 \\
\hline 26 & 87 & 0.211 & 2.006 & 2.29 & -2.636 & 2.508 & 1.761 & 7.079 \\
\hline 27 & 87 & 0.364 & 2.234 & 3.031 & -2.914 & 2.949 & 4.066 & 22.522 \\
\hline 30 & 87 & 0.373 & 1.867 & 2.725 & -2.892 & 2.687 & 6.027 & 46.440 \\
\hline 40 & 87 & 0.337 & 1.842 & 2.474 & -2.982 & 2.724 & 4.539 & 31.268 \\
\hline 50 & 85 & 0.277 & 0.916 & 0.987 & -2.743 & 2.729 & 1.471 & 17.361 \\
\hline 60 & 82 & 0.114 & 0.406 & 0.318 & -2.809 & 2.807 & -3.598 & 25.216 \\
\hline
\end{tabular}



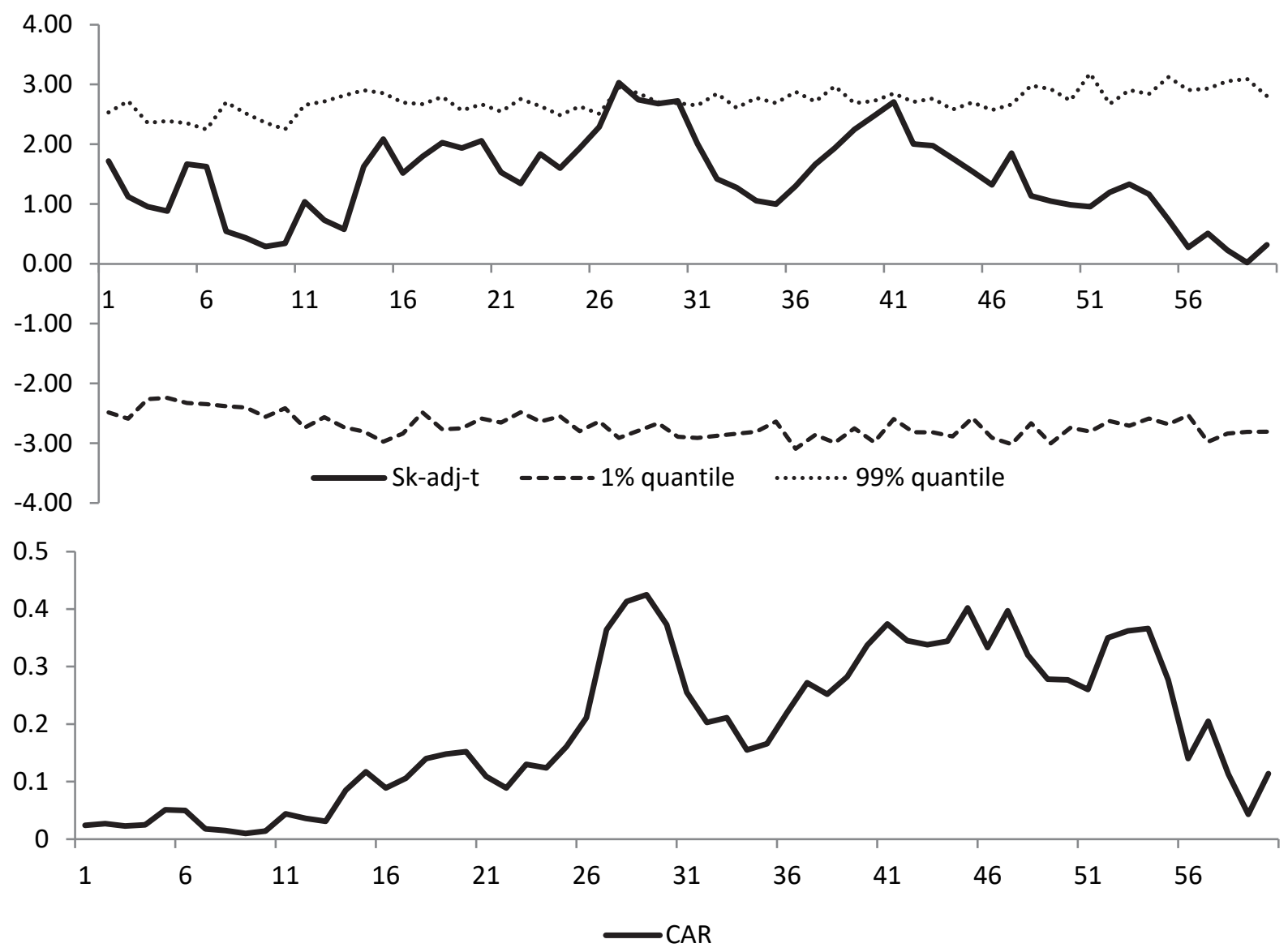

Fig. 3. Average BHAR Results Based on Matching Firm Abnormal Returns

Table 5 presents the results from a comparison with the benchmarking portfolio. Generally, the BHARs are smaller in value than those obtained with matching firms' benchmarks. Once again the BHAR has a positive and insignificant mean return through the hold period, it is positive at month one (3\%), rising to the highest and insignificant mean return of $20.6 \%$ after 29 months, three years and one month after the event date. Beyond 29 months the rate of decline accelerates, with abnormal returns reaching $18.4 \%$ after 4 years and $-2.7 \%$ after 5 years. The skewness and kurtosis of the BHAR based on matching firms is greater than under the benchmark S\&P500. The difference being attributable to the new issue and rebalancing issue in the benchmark portfolio compared to the matching firm benchmark.

Table 5

$\underline{\text { Summary Statistic for BHAR Using the Market Portfolio as a Benchmark }}$

\begin{tabular}{|c|c|c|c|c|c|c|c|c|}
\hline Month & $\mathbf{N}$ & Mean & t-stat & Adj-SK-t & F1-1\%b & F1-99\%b & Skewness & Kurtosis \\
\hline 1 & 87 & 0.003 & 0.222 & 0.229 & -2.517 & 2.314 & 0.356 & 1.531 \\
\hline 10 & 87 & 0.014 & 0.395 & 0.439 & -2.530 & 2.634 & 1.883 & 5.973 \\
\hline 20 & 87 & 0.140 & 1.476 & 1.916 & -2.753 & 3.025 & 4.597 & 27.909 \\
\hline 30 & 87 & 0.206 & 1.023 & 1.344 & -3.168 & 2.850 & 5.815 & 41.726 \\
\hline 40 & 87 & 0.027 & 0.147 & 0.232 & -2.537 & 2.855 & 4.570 & 28.741 \\
\hline 50 & 85 & 0.193 & 0.752 & 0.892 & -2.866 & 2.908 & 3.635 & 18.299 \\
\hline 60 & 82 & -0.027 & -0.143 & -0.117 & -2.769 & 2.307 & 1.361 & 1.634 \\
\hline
\end{tabular}



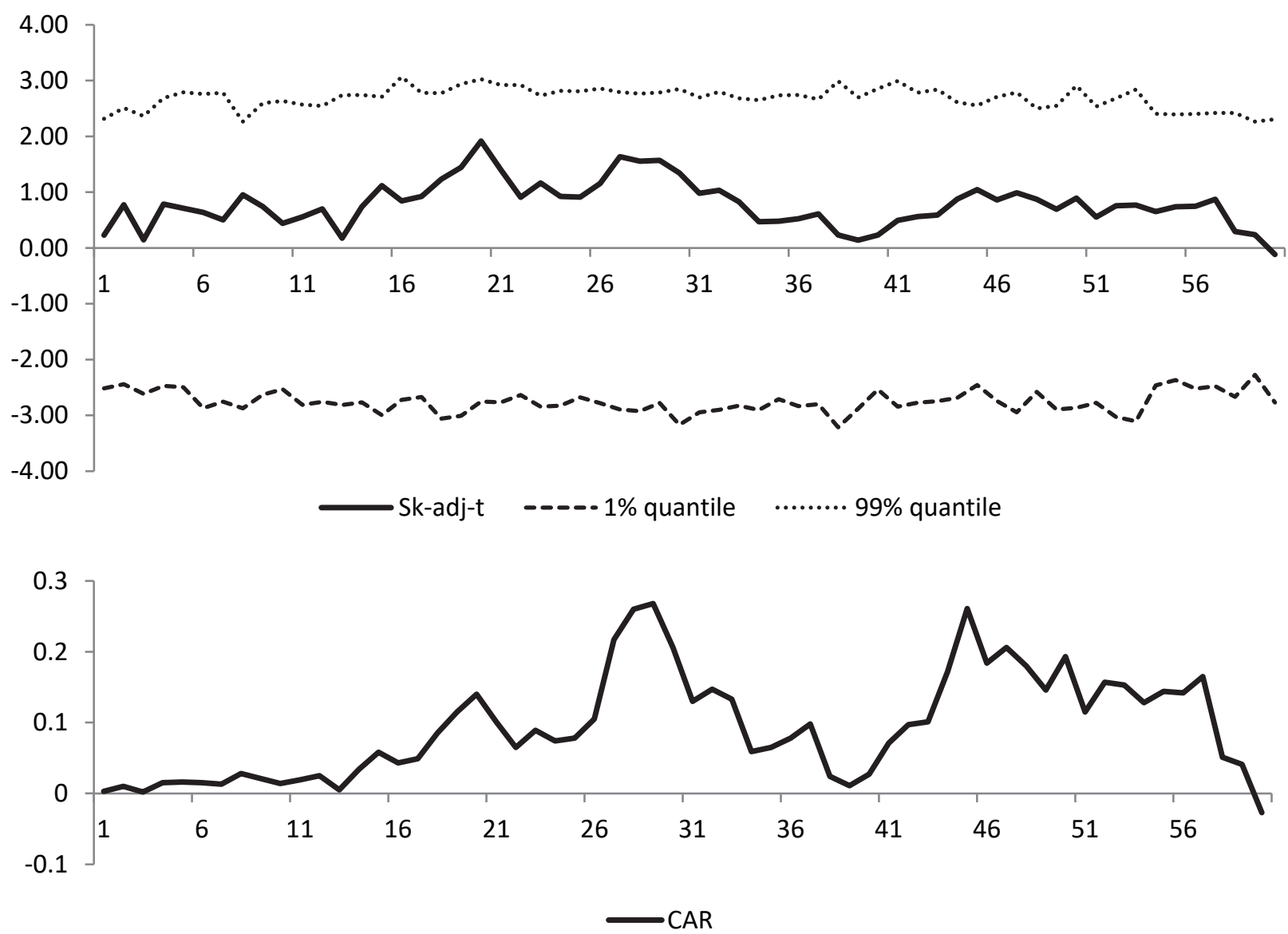

Fig. 4. Average BHAR Results Based on Market Index Abnormal Returns

There is a quite obvious difference between BHAR and CAR. CARs look more stable than BHAR when using matching firms to calculate the abnormality. On the other hand, the results based on the market benchmark are essentially the same and the produced curves are identical in most time periods. Even within BHAR itself. BHAR calculated using a matching firm appears greater than when using the benchmark market portfolio (S\&P500). Overall, the behaviour of the aggregate abnormal return, CAR and BHAR, clearly appear to be sensitive to the method adopted to gauge the abnormality. Furthermore, BHAR based on matching firms grow faster than when based on the S\&P500 benchmark especially after the adoption date where BHAR increased by more than 1.5 times. As discussed in the previous section the aggregate abnormal return, BHAR and CAR, is always highly skewed and leptokurtic and we suggest the wild bootstrapping (as discussed in methodology section) as a correction for these biases. This section will highlight the results of the bootstrap and the result of testing the null hypothesis that the aggregate abnormal returns, CAR and BHAR, are zero. The full version of the bootstrap test and tables are provided in Appendix (2). Fig. 3 depicts the skewness-adjusted $t$-statistic for the holding periods (60 months). The dotted and dashed lines are the $5^{\text {th }}$ and $95^{\text {th }}$ percentiles of the bootstrapped distribution. These can be interpreted at either the $5 \%$ critical value level for a one tail test, or the $10 \%$ critical value for a two-tail test. The graphs describe the two schemes of benchmarking: S\&P500 portfolio and matching firms have a similar pattern but express different messages. The two graphs have the same feature which is that outperformance increases at around month 13 but there is then a slight variation with a different and insignificant range. For the BHAR-based market benchmark portfolio scheme the insignificancy remains hold throughout the holding period and the outperformance accelerates to reach the highest volume in month 20. Following this it is slightly volatile and reaches the lowest point of outperformance in month 39 after which it dramatically increases until month 45 where it then appears stable to the end of the holding period. Similarly, the BHAR based on matching firms copies its counterpart but the outperformance ceases from being significant at around the $25-31$ month and 37- 42 month period. However, the aggregate $\mathrm{BH}$ return rapidly decreases after month 47 to reach close to zero as shown in Figure 4.

The CAR based on the matching benchmark provides a different story: the graph in Figure 4 shows that CAR behaviour becomes more erratic and is no longer significant beginning from around the period 25-31 months. The performance of the adopting firms is quite low, almost zero after the adoption date and sometimes underperforms the matching firms as depicted in Fig. 4. 
In general, the purpose of this paper is to investigate whether the adoption of EVA as a compensation and management plan will positively affect the performance of adopting companies. The paper compares the performance of adopting firms to that of selected matching firms and to the market indexes particularly the S\&P500 portfolio. Then it uses two common aggregating methods to test the event of adopting EVA by different US firms namely the CAR and BHAR methods. The results obtained however, showed a slight improvement in the performance of companies adopting EVA within five years from the date of adoption. This is implicitly in line with what Wallace (1997) concludes in this regard. Wallace indicated that adopting EVA will encourage managers to take decisions that will lead to efficiently using the firm's assets to increase the wealth of shareholders and the value of firms through taking accurate decisions regarding the investing, financing and operating activities. This, in turn, will be reflected in the price of shares in the stock market, therefore improving the performances of these stocks.

Similarly, the results achieved is incompatible with that of Kleiman (1999) where he compares the performance of firms adopting EVA to the performance two set of matching firms, the industry peer and closest match peer. By comparing the median of abnormal return he found that EVA adopter's show better performance after the adoption and outperform both the industry peer and closest peer match firms. The adjusted market return increases from $2.8 \%$ to $28.8 \%$ through three year time period after the adoption for the industry peer and from $2.6 \%$ to $7.8 \%$ for the closest match peer. However, the increases in performance of the adopting firms are still quite low. I used the mean of CAR and BHAR to compare the performances of adopting firms to those matching firms and market benchmark portfolio (S\&P500 index) and the result revealed that EVA's firms outperform those matching and S\&P500 portfolio and the CAR increases to reach $8.85 \%$ and 36.6\% for matching firms and benchmark index respectively and the BHAR increases to $6.6 \%$ and $26.8 \%$ for the same order.

\section{Conclusion}

This paper has described the research design and the methodology that was used to examine the EVA adoption event. Both the CAR and the BHAR approaches were adopted to conduct our study. The previous research has been extended by increasing the number of EVA adopter firms to 89 and the time horizon of the study to cover the firms' performance during the period 19602012 was also extended. In addition, wild bootstrapping and using the skewness adjusted t-statistic to enhance the statistical reliability of the event test statistics was adopted. By doing this all three moments of the parent distribution of the test statistic (heteroscedasticity, skewness and kurtosis) were taken into account. Furthermore, the criterion to select the matching firms was carefully applied as was the problem of delisting.

The results obtained in this research are consistent with the previous studies' results discussed in section 5.2. Regardless of the methodology approach, CAR or BHAR, the results of this chapter reveal that firms adopting EVA as a compensation plan and management tool outperform the market (S\&P500) and matching firms (same sector) most of the time within the hold period. The CAR results show that despite the benchmarking used the majority of adopter firms positively outperform the matching firms and the S\&P500 portfolio and for a few months the adopter firms have a negative performance mainly in year one and year five of the 10 year estimated period. In general, CAR appears more stable and has the lowest skewed and leptokurtic.

Regarding the BHAR approach the findings reveal that the mean return of the adopter firms is both positive and highly skewed and leptokurtic throughout the holding period. Generally, the results obtained from a comparison against the benchmarking portfolio (S\&P500) are smaller in value than those obtained when compared to the matching firms' benchmark. One interesting finding is that CAR is almost the same as BHAR when the S\&P500 portfolio is used as a benchmark to calculate the aggregate returns.

To sum up, irrespective of the aggregation approach used to measure the abnormal return, the adopter firms have a considerably low outperformance and this outperformance increased as the hold period increased. However, even with the positive performances most EVA adopter firms' outperformance declines after the adoption and takes some time to return to negative performance when matching benchmarks are used. This might typically reflect the fact that the market might react poorly to the adoption announcement. Finally, by analysing the adopter firms' performance we recognize that the adoption exists after a period of bad performances. 


\section{References}

Balachandran, S. (2006). How does income affect investment? The role of prior performance measures. Management Science. 52(3), 383-394.

Barber, B. \& Lyon, J. (1997). Detecting long-run abnormal stock returns: The empirical power and specification of test statistics. Journal of Financial Economics, 43(3), 341-372.

Barber, B. \& Lyon, J. (1996). Detecting abnormal operating performance: The empirical power and specification of test statistics, Journal of Financial Economics, 41(3), 359-399.

Davidson, J., Monticini, A. \& Peel, D. (2007). Implementing the wild bootstrap using a two-point distribution. Economics Letters, 96(3), 309-315.

Drucker, P.F. (1995). The information executives truly need. Harvard Business Review, January- February, 54-62.

Edey, H. C. (1957). Business Valuation, Goodwill and the Super-Profit Method. Accountancy [Reprinted in Studies in Accounting Theory, edited by W. T. Baxter and S. David-son, pp. 201-217. Burr Ridge, Ill.: Irwin, 1962.]

Fama, E. F. (1998). Market efficiency, long-term returns, and behavioural finance. Journal of Financial Economics, 49(3), 283306.

Fama, F., Fisher, L., Jenson, M., \& Roll, R. (1969). The adjustment of stock prices to new information. International Economic Review, 10(1), 1-21.

Ferguson, R., Rentzler, J., \& Yu, S. (2005). Does economic value added (EVA) improve stock performance profitability?. The Journal of Applied Finance, Fall/Winter, 101-113.

Hogan, C. E., \& Lewis, C. M., (2005). Long-run investment decisions, operating performance, and shareholder value creation plans based on economic profit. Journal of Finance and Quantitative analysis. 40(4), 721-745.

Johnson, N. J. (1978). Modified t test and confidence intervals for asymmetrical population. Journal of the American Statistical Association. 73(363), 536-544.

Kleiman, T. R. (1999). Some new evidence on EVA Companies. Journal of Applied Corporate Finance, 12(2), 80-91.

Kothari, S. P. \& Warner, J. B. (1997). Measuring long-horizon security price performance. Journal of Financial Economics, 43(3), 301-339.

Lambert, R. A. (1993). The use of accounting and security price measures of performance in managerial compensation contracts, A Discussion. Journal of Accounting and Economics, 16, 101-123.

Liu, R. Y., (1988). Bootstrap procedure under some non-I.I.D models. Journal of Statistics, 16(4), 1696-1708.

Liu, W. \& Strong, N. (2006). Biases in decomposing holding period portfolio returns. Review of Financial Studies, 21(5), 22432274.

Lyon, J., Barber, B. \& Tsai, C. (1999). Improved methods for tests of long-run abnormal stock returns. Journal of Finance, 54(1), 165-201.

Malmi, T. \& Ikaheimo, S. (2003). Value based management practices - Some evidence from the field. Management Accounting Research, 14(3), 235-254.

Mammen, E. (1993). Bootstrap and wild bootstrap for high dimensional linear models. Annals of Statistics, 21(1), 255-285.

Mitchell, M.L. \& Stafford, E. (2000). Managerial decisions and long-term stock price performance. The Journal of Business, 73(3), 287-320.

Mramor, D., \& Valentincic, A., (2001). When maximizing shareholders' wealth is not the only choice. Eastern European Economics, 39(6), 64-93.

Myers, R. (1997). Measure for measure. CFO Magazine, November. CANNING, J. B. The Economics of Accountancy. New York: Ronald Press, 1929.

Preinreich, G.A.D. (1937). Valuation and amortization. The Accounting Review, 12(3), 209-226.

Stern, J.M, Stewart, G.B. \& Chew, D.H., (1991). The EVA financial management system. Journal of Applied Corporate Finance, 8(2), 32-46.

Stuart, E. A. (2010). Matching methods for causal inference: A review and a look forward. Statistical Science, 25(1), 1-21.

Tortella, D. B. \& Brusco, S. (2003). The economic value added (EVA): An analysis of market reaction. Advances in Accounting, $20,265-290$.

Wallace, J. (1997). Adopting residual income-based compensation plans: Do you get what you pay for?. Journal of Accounting and Economics, 24(3), 275-300. 


\section{Appendix 1}

EVA Adopting Companies 1987-2001(USA) and Control Companies

\begin{tabular}{|c|c|c|c|c|}
\hline NO. & SAMPLE COMPANY & ADOPTION YEAR & CONTROL COMPANY & SIC CODE \\
\hline 1 & COCA COLA & 1987 & PEPSICO INC & 2080 \\
\hline 2 & CSX CORPORATION & 1988 & SANTA FE FINANCIAL CORP & 6711 \\
\hline 3 & CILCORP & 1989 & ALLETE INC & 4931 \\
\hline 4 & CRANE CO & 1990 & WHITTAKER CORP & $3490 / 3494$ \\
\hline 5 & BRIGGS \& STRATTON & 1990 & STEWART \& STEVENSON SVCS INC & $3510 / 3519$ \\
\hline 6 & QUAKER OATS & 1991 & RALSTON PURINA CO & $2040 / 2043$ \\
\hline 7 & BALL CORP & 1992 & CROWN HOLDINGS INC & 3221 \\
\hline 8 & WHIRLPOOL CORP & 1992 & AKTIEBOLAGET ELECTROLUX & 3630 \\
\hline 9 & AT\&T & 1992 & G T E CORP & 4813 \\
\hline 10 & SCHERER, R.P. & 1992 & FOREST LABS INC & 2834 \\
\hline 11 & WELLMAN & 1993 & ASHLAND INC NEW & 2824 \\
\hline 12 & GRAINGER, W.W. & 1993 & WAXMAN INDUSTRIES INC & 5063 \\
\hline 13 & MANITOWOC CO & 1993 & ASTEC INDUSTRIES INC & 3531 \\
\hline 14 & DIGITAL EQUIPMENT CORP & 1993 & APPLE INC & 3573 \\
\hline 15 & FURON CORP. & 1993 & WYNNS INTERNATIONAL INC & 3079 \\
\hline 16 & HARNISCHFEGER IND. INC. & 1993 & APPLIED MATERIALS INC & 3536 \\
\hline 17 & HEWLETT PACKARD CO. & 1993 & HITACHI LIMITED & 3571 \\
\hline 18 & RUBY TUESDAY INC. & 1993 & WORLDWIDE RESTAURANT CNCPTS INC & 5812 \\
\hline 19 & SMITH INTERNATIONAL INC. & 1993 & CABOT CORP & 3533 \\
\hline 20 & TRANSAMERICA CORP & 1993 & LOEWS CORP & 6711 \\
\hline 21 & ACXIOM CORP & 1994 & MCGRAW HILL COS INC & 7370 \\
\hline 22 & BOISE CASCADE CORP & 1994 & BT OFFICE PRODUCTS INTL INC & 2421 \\
\hline 23 & FLEMING COMPANIES INC & 1994 & NASH FINCH COMPANY & 5141 \\
\hline 24 & GEORGIAPACIFIC GROUP & 1994 & WEYERHAEUSER CO & 2435 \\
\hline 25 & LILLY (ELI) \& CO & 1994 & WYETH & 2834 \\
\hline 26 & SPRINT FON GROUP & 1994 & CENTEL CORP & 4813 \\
\hline 27 & CENTURA BANKS INC & 1994 & AMERICAN FLETCHER CORP & 6036 \\
\hline 28 & CORE INDUSTRIES INC. & 1994 & WHITTAKER CORP & 3429 \\
\hline 29 & DEERE \& CO. & 1994 & KUBOTA CORP & 3523 \\
\hline 30 & EASTMAN CHEMICAL CO. & 1994 & ROHM \& HAAS CO & 3861 \\
\hline 31 & GENCORP INC. & 1994 & LOCKHEED MARTIN CORP & 3011 \\
\hline 32 & INCSTAR CORP. & 1994 & A M A G PHARMACEUTICALS INC & 2830 \\
\hline 33 & INSTEEL INDUSTRIES & 1994 & NATIONAL STANDARD CO & 3310 \\
\hline 34 & OHIO EDISON CO. & 1994 & NORTHEAST UTILITIES & 4911 \\
\hline 35 & REYNOLDS METALS CO. & 1994 & KAISERTECH LTD & 3353 \\
\hline 36 & TENNECO INC. & 1994 & CHAMPION PARTS INC & 3714 \\
\hline 37 & WALLACE COMPUTER SERVICES & 1994 & MOORE WALLACE INC & 2761 \\
\hline 38 & ZOLTEK COS. INC. & 1994 & WOODWARD INC & 3620 \\
\hline 39 & ARMSTRONG HOLDINGS INC & 1995 & NEWELL RUBBERMAID INC & 2511 \\
\hline 40 & BARD (C.R.) & 1995 & TELEFLEX INC & 5086 \\
\hline 41 & PERKINELMER INC & 1995 & BIO RAD LABORATORIES INC & 3823 \\
\hline 42 & SPX CORP & 1995 & GIDDINGS \& LEWIS INC WIS & 3540 \\
\hline 43 & AMERICAN PRECISION IND. & 1995 & FRANKLIN ELECTRIC INC & 3443 \\
\hline 44 & ARMSTRONG WORLD INDUSTRIES & 1995 & E G \& G INC (VISKASE COMPANIES) & 2511 \\
\hline 45 & BECKMAN INSTRUMENTS INC. & 1995 & PERKINELMER INC & 5311 \\
\hline 46 & EMERSON ELECTRIC CO. & 1995 & PANASONIC CORP & $3621 / 3823$ \\
\hline 47 & IPALCO ENTERPRISES INC. & 1995 & TUCSON /U N S ENERGY CORP & 4911 \\
\hline 48 & KAISER ALLUMINUM CORP. & 1995 & MAXXAM INC & 3334 \\
\hline 49 & KNIGHT-RIDDER INC. & 1995 & NEW YORK TIMES CO & 2711 \\
\hline 50 & NEW JERSEY RESOURCES & 1995 & ATMOS ENERGY CORP & 4924 \\
\hline 51 & SEQUENT COMPUTER & 1995 & STRATUS COMPUTER INC & 3570 \\
\hline 52 & ADC TELECOMMUNICATIONS INC & 1996 & TELLABS INC & 3679 \\
\hline 53 & BAUSCH \& LOMB INC & 1996 & CHIRON CORP & 3861 \\
\hline 54 & BECTON DICKINSON \& CO & 1996 & BARD C R INC & 3841 \\
\hline 55 & DONNELLEY (R R) \& SONS CO & 1996 & BOWNE \& CO INC & 3229 \\
\hline 56 & GUIDANT CORP & 1996 & MEDTRONIC INC & 3841 \\
\hline 57 & KANSAS CITY POWER \& LIGHT & 1996 & C M P GROUP INC & 4911 \\
\hline 58 & OLIN CORP & 1996 & F M C CORP & 2810 \\
\hline 59 & SILICON VY BANCSHARES & 1996 & AMSOUTH BANCORPORATION & $6022 / 6710$ \\
\hline 60 & TUPPERWARE CORP & 1996 & ENVIRODYNE INDUSTRIES INC & 3089 \\
\hline
\end{tabular}


Appendix 1. Continued.

\begin{tabular}{|c|c|c|c|c|}
\hline NO. & SAMPLE COMPANY & $\begin{array}{l}\text { ADOPTION } \\
\text { YEAR }\end{array}$ & CONTROL COMPANY & SIC CODE \\
\hline 61 & MILLER HERMAN & 1996 & H N I CORP & 2531 \\
\hline 62 & CINCINNATI MILACRON & 1996 & KENNAMETAL INC & 3541 \\
\hline 63 & HACH CO. & 1996 & COHERENT INC & 3820 \\
\hline 64 & KLLM TRANSPORT SERVICES & 1996 & MATLACK SYSTEMS INC & 4210 \\
\hline 65 & NEW ENGLAND BUSINESS SERVICES & 1996 & ENNIS INC & 2761 \\
\hline 66 & QUAKER STATE & 1996 & TESORO CORP & 2911 \\
\hline 67 & STRATTEC SECURITY CORP & 1996 & F M C CORP & 8740 \\
\hline 68 & TEKTRONIX & 1996 & SNAP ON INC & 3825 \\
\hline 69 & CDI CORP & 1997 & ROBERT HALF INTL INC & 3269 \\
\hline 70 & GC COMPANIES INC & 1997 & MARCUS CORP & 7830 \\
\hline 71 & JOHNSON OUTDOORS INC & 1997 & ELECTRO SCIENTIFIC INDS INC & 3940 \\
\hline 72 & MILLENNIUM CHEMICALS INC & 1997 & BIG THREE INDS INC & 2813 \\
\hline 73 & PHARMACIA CORP & 1997 & BAUSCH \& LOMB INC & 2823 \\
\hline 74 & RYDER SYSTEM INC & 1997 & ROLLINS TRUCK LEASING CORP & 6159 \\
\hline 75 & TENET HEALTHCARE CORP & 1997 & UNIVERSAL HEALTH SERVICES INC & 8062 \\
\hline 76 & WEBSTER FINL CRP WATERBURY & 1997 & AMSOUTH BANCORPORATION & 6035 \\
\hline 77 & FEDERALMOGUL CORP & 1998 & DANA HOLDING CORP & 3562 \\
\hline 78 & MATERIAL SCIENCES CORP & 1998 & SHAW GROUP INC & 3470 \\
\hline 79 & MONTANA POWER CO & 1998 & C H ENERGY GROUP INC & 4911 \\
\hline 80 & PENNEY (J C) CO & 1998 & DILLARDS INC & 5311 \\
\hline 81 & STANDARD MOTOR PRODS & 1998 & HARBINGER GROUP INC & 3694 \\
\hline 82 & BRADLEY PHARMACEUTICALS & 1998 & BALCHEM CORP & $2830 / 5120$ \\
\hline 83 & BEST BUY CO INC & 1998 & RADIOSHACK CORP & 5732 \\
\hline 84 & INTERNATIONAL MULTIFOODS & 1999 & RALSTON PURINA CO & 2041 \\
\hline 85 & TOYS R US INC & 1999 & MICHAELS STORES INC & 6711 \\
\hline 86 & GENESCO & 1999 & FOOT LOCKER INC & 2341 \\
\hline 87 & MOLSON COORS & 1999 & ANHEUSER BUSCH COS INC & 2082 \\
\hline 88 & SCHNITZER STEEL & 2000 & ENVIROSOURCE INC & 3310 \\
\hline 89 & HARSCO & 2001 & DYNAMIC MATERIALS CORP & 3446 \\
\hline
\end{tabular}

Source: Wallace, 1997 and Kleiman (1999), Stern Stewart \& Co. brochure, Lexis-Nexis, Proxy Statement and 10-Q report and Wall Street Journal. 
Appendix 2: Full version of the bootstrap

Table A2

Matching firm based cumulative abnormal returns (CAR)

\begin{tabular}{|c|c|c|c|c|c|c|c|c|}
\hline Month & $\mathbf{N}$ & Mean & t-stat & Adj-SK-t & F1-1\%b & F1-99\%b & Skewness & Kurtosis \\
\hline 1 & 87 & 0.024 & 1.599 & 1.719 & -2.562 & 2.358 & 1.104 & 3.605 \\
\hline 2 & 87 & 0.028 & 1.160 & 1.163 & -2.549 & 2.73 & 0.037 & 7.417 \\
\hline 3 & 87 & 0.021 & 0.801 & 0.83 & -2.381 & 2.422 & 0.711 & 2.073 \\
\hline 4 & 87 & 0.025 & 0.881 & 0.908 & -2.552 & 2.442 & 0.588 & 2.004 \\
\hline 5 & 87 & 0.044 & 1.452 & 1.481 & -2.294 & 2.4 & 0.310 & 0.567 \\
\hline 6 & 87 & 0.038 & 1.284 & 1.298 & -2.335 & 2.427 & 0.180 & 1.042 \\
\hline 7 & 87 & 0.009 & 0.276 & 0.28 & -2.462 & 2.423 & 0.206 & 1.239 \\
\hline 8 & 87 & -0.006 & -0.183 & -0.187 & -2.427 & 2.419 & -0.209 & 0.337 \\
\hline 9 & 87 & -0.006 & -0.180 & -0.186 & -2.394 & 2.351 & -0.311 & 0.146 \\
\hline 10 & 87 & -0.005 & -0.145 & -0.151 & -2.26 & 2.423 & -0.289 & 0.600 \\
\hline 11 & 87 & 0.022 & 0.595 & 0.596 & -2.512 & 2.406 & 0.018 & 0.958 \\
\hline 12 & 87 & 0.016 & 0.388 & 0.38 & -2.536 & 2.497 & -0.336 & 1.909 \\
\hline 13 & 87 & 0.003 & 0.070 & 0.068 & -2.267 & 2.146 & -0.158 & 2.011 \\
\hline 14 & 87 & 0.046 & 1.058 & 1.068 & -2.313 & 2.68 & 0.162 & 1.116 \\
\hline 15 & 87 & 0.069 & 1.526 & 1.543 & -2.594 & 2.268 & 0.166 & 1.275 \\
\hline 16 & 87 & 0.059 & 1.303 & 1.326 & -2.258 & 2.516 & 0.302 & 0.577 \\
\hline 17 & 87 & 0.065 & 1.429 & 1.439 & -2.495 & 2.688 & 0.108 & 0.587 \\
\hline 18 & 87 & 0.075 & 1.502 & 1.543 & -2.613 & 2.398 & 0.416 & 1.457 \\
\hline 19 & 87 & 0.072 & 1.319 & 1.387 & -2.396 & 2.638 & 0.848 & 2.319 \\
\hline 20 & 87 & 0.079 & 1.454 & 1.521 & -2.601 & 2.327 & 0.721 & 2.139 \\
\hline 21 & 87 & 0.033 & 0.674 & 0.683 & -2.514 & 2.29 & 0.273 & 1.144 \\
\hline 22 & 87 & 0.026 & 0.527 & 0.526 & -2.433 & 2.224 & -0.023 & 0.814 \\
\hline 23 & 87 & 0.052 & 1.044 & 1.037 & -2.47 & 2.695 & -0.122 & 0.341 \\
\hline 24 & 87 & 0.040 & 0.754 & 0.757 & -2.285 & 2.224 & 0.073 & 0.754 \\
\hline 25 & 87 & 0.071 & 1.272 & 1.302 & -2.229 & 2.437 & 0.394 & 1.352 \\
\hline 26 & 87 & 0.101 & 1.708 & 1.768 & -2.429 & 2.352 & 0.494 & 1.298 \\
\hline 27 & 87 & 0.146 & 2.157 & 2.365 & -2.568 & 2.653 & 1.126 & 4.581 \\
\hline 28 & 87 & 0.147 & 2.070 & 2.315 & -2.863 & 2.661 & 1.433 & 8.619 \\
\hline 29 & 87 & 0.152 & 2.104 & 2.360 & -2.831 & 2.758 & 1.451 & 8.893 \\
\hline 30 & 87 & 0.140 & 1.984 & 2.192 & -2.562 & 2.563 & 1.312 & 7.815 \\
\hline 31 & 87 & 0.108 & 1.480 & 1.533 & -2.563 & 2.655 & 0.548 & 5.698 \\
\hline 32 & 87 & 0.061 & 0.819 & 0.865 & -2.710 & 2.368 & 1.105 & 7.834 \\
\hline 33 & 87 & 0.043 & 0.541 & 0.572 & -2.679 & 2.708 & 1.089 & 8.359 \\
\hline 34 & 87 & 0.026 & 0.312 & 0.329 & -2.519 & 2.475 & 0.774 & 6.823 \\
\hline 35 & 87 & 0.024 & 0.279 & 0.291 & -2.527 & 2.569 & 0.587 & 7.305 \\
\hline 36 & 87 & 0.030 & 0.343 & 0.354 & -2.435 & 2.52 & 0.532 & 6.817 \\
\hline 37 & 87 & 0.071 & 0.847 & 0.879 & -2.742 & 2.654 & 0.757 & 5.666 \\
\hline 38 & 87 & 0.084 & 1.022 & 1.049 & -2.437 & 2.656 & 0.488 & 4.295 \\
\hline 39 & 87 & 0.098 & 1.173 & 1.198 & -2.509 & 2.391 & 0.364 & 4.015 \\
\hline 40 & 87 & 0.122 & 1.424 & 1.467 & -2.579 & 2.536 & 0.473 & 3.991 \\
\hline 41 & 87 & 0.150 & 1.757 & 1.843 & -2.551 & 2.421 & 0.674 & 4.038 \\
\hline 42 & 86 & 0.080 & 0.821 & 0.838 & -2.309 & 2.443 & 0.401 & 4.149 \\
\hline 43 & 86 & 0.060 & 0.585 & 0.598 & -2.331 & 2.429 & 0.425 & 3.237 \\
\hline 44 & 86 & 0.033 & 0.314 & 0.326 & -2.635 & 2.254 & 0.553 & 3.481 \\
\hline 45 & 86 & 0.020 & 0.171 & 0.178 & -2.813 & 2.572 & 0.378 & 4.421 \\
\hline 46 & 85 & 0.014 & 0.116 & 0.118 & -2.546 & 2.634 & 0.104 & 4.501 \\
\hline 47 & 85 & 0.033 & 0.280 & 0.285 & -2.207 & 2.419 & 0.280 & 3.228 \\
\hline 48 & 85 & 0.015 & 0.119 & 0.119 & -2.515 & 2.662 & -0.023 & 3.568 \\
\hline 49 & 85 & -0.003 & -0.026 & -0.024 & -2.657 & 2.336 & 0.117 & 3.556 \\
\hline 50 & 85 & -0.017 & -0.140 & -0.136 & -2.332 & 2.452 & 0.233 & 3.597 \\
\hline 51 & 85 & -0.025 & -0.200 & -0.196 & -2.329 & 2.409 & 0.181 & 3.441 \\
\hline 52 & 85 & 0.053 & 0.420 & 0.421 & -2.468 & 2.643 & 0.049 & 3.528 \\
\hline 53 & 85 & 0.077 & 0.626 & 0.629 & -2.597 & 2.63 & 0.103 & 3.763 \\
\hline 54 & 85 & 0.088 & 0.718 & 0.711 & -2.436 & 2.322 & -0.174 & 3.531 \\
\hline 55 & 84 & 0.052 & 0.408 & 0.401 & -2.351 & 2.690 & -0.301 & 3.115 \\
\hline 56 & 84 & 0.004 & 0.033 & 0.022 & -2.319 & 2.430 & -0.593 & 3.500 \\
\hline 57 & 84 & -0.003 & -0.022 & -0.03 & -2.657 & 2.293 & -0.424 & 2.862 \\
\hline 58 & 83 & -0.037 & -0.275 & -0.285 & -2.470 & 2.363 & -0.476 & 3.240 \\
\hline 59 & 82 & -0.035 & -0.262 & -0.272 & -2.493 & 2.821 & -0.465 & 3.126 \\
\hline 60 & 82 & -0.032 & -0.245 & -0.254 & -2.404 & 2.480 & -0.424 & 2.574 \\
\hline
\end{tabular}


Table A3. Market Benchmark Based Cumulative Abnormal Return

\begin{tabular}{|c|c|c|c|c|c|c|c|c|}
\hline Month & $\mathbf{N}$ & Mean & t-stat & Adj-SK-t & F1-1\%b & F1-99\%b & Skewness & Kurtosis \\
\hline 1 & 87 & 0.003 & 0.222 & 0.229 & -2.519 & 2.456 & 0.356 & 1.531 \\
\hline 2 & 87 & 0.011 & 0.852 & 0.891 & -2.465 & 2.211 & 0.885 & 2.127 \\
\hline 3 & 87 & 0.003 & 0.219 & 0.23 & -2.415 & 2.609 & 0.545 & 2.396 \\
\hline 4 & 87 & 0.016 & 0.871 & 0.898 & -2.363 & 2.343 & 0.584 & 3.135 \\
\hline 5 & 87 & 0.014 & 0.664 & 0.687 & -2.454 & 2.762 & 0.698 & 4.973 \\
\hline 6 & 87 & 0.014 & 0.663 & 0.697 & -2.665 & 2.773 & 1.015 & 5.989 \\
\hline 7 & 87 & 0.014 & 0.580 & 0.616 & -2.741 & 2.451 & 1.214 & 5.324 \\
\hline 8 & 87 & 0.026 & 0.984 & 1.027 & -2.365 & 2.5 & 0.807 & 2.016 \\
\hline 9 & 87 & 0.026 & 0.993 & 1.054 & -2.506 & 2.589 & 1.160 & 2.549 \\
\hline 10 & 87 & 0.013 & 0.479 & 0.507 & -2.711 & 2.445 & 1.097 & 2.635 \\
\hline 11 & 87 & 0.020 & 0.718 & 0.766 & -2.606 & 2.383 & 1.323 & 3.711 \\
\hline 12 & 87 & 0.024 & 0.785 & 0.816 & -2.269 & 2.367 & 0.771 & 2.318 \\
\hline 13 & 87 & 0.000 & -0.014 & 0.008 & -2.567 & 2.649 & 1.233 & 6.009 \\
\hline 14 & 87 & 0.024 & 0.682 & 0.722 & -2.447 & 2.546 & 1.152 & 5.598 \\
\hline 15 & 87 & 0.040 & 1.059 & 1.13 & -2.442 & 2.761 & 1.230 & 5.891 \\
\hline 16 & 87 & 0.038 & 1.062 & 1.159 & -2.467 & 2.508 & 1.666 & 5.495 \\
\hline 17 & 87 & 0.043 & 1.128 & 1.227 & -2.662 & 2.579 & 1.560 & 4.264 \\
\hline 18 & 87 & 0.054 & 1.246 & 1.388 & -2.483 & 2.542 & 1.935 & 6.541 \\
\hline 19 & 87 & 0.062 & 1.324 & 1.478 & -2.439 & 2.676 & 1.908 & 6.382 \\
\hline 20 & 87 & 0.085 & 1.848 & 2.091 & -2.477 & 2.551 & 1.737 & 5.677 \\
\hline 21 & 87 & 0.063 & 1.332 & 1.447 & -2.441 & 2.589 & 1.421 & 3.920 \\
\hline 22 & 87 & 0.041 & 0.832 & 0.875 & -2.435 & 2.491 & 1.003 & 2.496 \\
\hline 23 & 87 & 0.060 & 1.217 & 1.292 & -2.666 & 2.491 & 1.051 & 3.104 \\
\hline 24 & 87 & 0.046 & 0.858 & 0.89 & -2.397 & 2.356 & 0.719 & 1.912 \\
\hline 25 & 87 & 0.054 & 0.979 & 1.017 & -2.417 & 2.545 & 0.741 & 1.901 \\
\hline 26 & 87 & 0.067 & 1.134 & 1.178 & -2.67 & 2.378 & 0.696 & 2.080 \\
\hline 27 & 87 & 0.085 & 1.253 & 1.348 & -2.728 & 2.685 & 1.281 & 4.510 \\
\hline 28 & 87 & 0.077 & 1.088 & 1.192 & -2.97 & 2.619 & 1.732 & 7.175 \\
\hline 29 & 87 & 0.081 & 1.145 & 1.261 & -2.761 & 2.668 & 1.793 & 7.532 \\
\hline 30 & 87 & 0.066 & 0.929 & 1.004 & -2.404 & 2.59 & 1.535 & 5.988 \\
\hline 31 & 87 & 0.050 & 0.722 & 0.775 & -2.453 & 2.657 & 1.456 & 5.323 \\
\hline 32 & 87 & 0.047 & 0.661 & 0.711 & -2.597 & 2.836 & 1.488 & 6.305 \\
\hline 33 & 87 & 0.013 & 0.175 & 0.2 & -2.639 & 2.463 & 1.347 & 6.595 \\
\hline 34 & 87 & -0.002 & -0.024 & -0.009 & -2.878 & 2.454 & 0.880 & 5.305 \\
\hline 35 & 87 & -0.003 & -0.035 & -0.024 & -2.321 & 2.489 & 0.626 & 6.095 \\
\hline 36 & 87 & -0.003 & -0.037 & -0.023 & -2.401 & 2.659 & 0.800 & 5.023 \\
\hline 37 & 87 & 0.023 & 0.296 & 0.325 & -2.469 & 2.772 & 1.407 & 4.560 \\
\hline 38 & 87 & 0.019 & 0.244 & 0.266 & -2.598 & 2.464 & 1.123 & 3.300 \\
\hline 39 & 87 & 0.014 & 0.178 & 0.196 & -2.334 & 2.582 & 0.994 & 3.021 \\
\hline 40 & 87 & 0.020 & 0.252 & 0.279 & -2.632 & 2.659 & 1.336 & 3.738 \\
\hline 41 & 87 & 0.051 & 0.643 & 0.685 & -2.483 & 2.639 & 1.305 & 3.550 \\
\hline 42 & 86 & 0.040 & 0.451 & 0.482 & -2.671 & 2.444 & 1.243 & 3.686 \\
\hline 43 & 86 & 0.036 & 0.392 & 0.419 & -2.517 & 2.448 & 1.109 & 3.625 \\
\hline 44 & 86 & 0.046 & 0.487 & 0.517 & -2.278 & 2.736 & 1.126 & 3.882 \\
\hline 45 & 86 & 0.042 & 0.426 & 0.45 & -2.656 & 2.626 & 0.975 & 4.307 \\
\hline 46 & 85 & 0.023 & 0.215 & 0.233 & -2.459 & 2.444 & 0.941 & 3.907 \\
\hline 47 & 85 & 0.044 & 0.404 & 0.433 & -2.571 & 2.881 & 1.182 & 3.816 \\
\hline 48 & 85 & 0.036 & 0.322 & 0.348 & -2.181 & 2.575 & 1.188 & 3.480 \\
\hline 49 & 85 & 0.024 & 0.218 & 0.246 & -2.691 & 2.329 & 1.390 & 3.665 \\
\hline 50 & 85 & 0.029 & 0.262 & 0.289 & -2.346 & 2.313 & 1.295 & 3.024 \\
\hline 51 & 85 & 0.007 & 0.063 & 0.084 & -2.421 & 2.582 & 1.146 & 2.415 \\
\hline 52 & 85 & 0.044 & 0.398 & 0.425 & -2.402 & 2.495 & 1.147 & 2.863 \\
\hline 53 & 85 & 0.065 & 0.610 & 0.651 & -2.63 & 2.254 & 1.294 & 2.955 \\
\hline 54 & 85 & 0.066 & 0.603 & 0.64 & -2.404 & 2.668 & 1.207 & 2.439 \\
\hline 55 & 84 & 0.065 & 0.577 & 0.607 & -2.385 & 2.653 & 0.985 & 1.989 \\
\hline 56 & 84 & 0.059 & 0.521 & 0.54 & -2.402 & 2.586 & 0.657 & 1.688 \\
\hline 57 & 84 & 0.062 & 0.544 & 0.564 & -2.691 & 2.268 & 0.703 & 1.587 \\
\hline 58 & 83 & 0.015 & 0.125 & 0.134 & -2.451 & 2.372 & 0.432 & 2.448 \\
\hline 59 & 82 & 0.028 & 0.238 & 0.253 & -2.536 & 2.369 & 0.722 & 2.495 \\
\hline 60 & 82 & 0.013 & 0.108 & 0.119 & -2.604 & 2.396 & 0.598 & 2.310 \\
\hline
\end{tabular}


Table A4

Summary Statistic for BHAR Matching firms

\begin{tabular}{|c|c|c|c|c|c|c|c|c|}
\hline Month & $\mathbf{N}$ & Mean & t-stat & $\begin{array}{c}\text { Adjusted Sk. } \\
\text { t-stat }\end{array}$ & $\begin{array}{c}1 \% \text { bootstrap } \\
\text { quantile }\end{array}$ & $\begin{array}{c}99 \% \text { bootstrap } \\
\text { quantile }\end{array}$ & Skewness & Kurtosis \\
\hline 1 & 87 & 0.024 & 1.599 & 1.719 & -2.487 & 2.533 & 1.104 & 3.605 \\
\hline 2 & 87 & 0.027 & 1.132 & 1.123 & -2.59 & 2.721 & -0.132 & 7.044 \\
\hline 3 & 87 & 0.023 & 0.918 & 0.954 & -2.262 & 2.356 & 0.753 & 1.094 \\
\hline 4 & 87 & 0.025 & 0.872 & 0.881 & -2.242 & 2.389 & 0.207 & 0.943 \\
\hline 5 & 87 & 0.051 & 1.658 & 1.667 & -2.327 & 2.35 & 0.085 & 0.199 \\
\hline 6 & 87 & 0.050 & 1.599 & 1.625 & -2.348 & 2.247 & 0.237 & 0.988 \\
\hline 7 & 87 & 0.018 & 0.535 & 0.544 & -2.382 & 2.702 & 0.335 & 1.485 \\
\hline 8 & 87 & 0.015 & 0.427 & 0.432 & -2.404 & 2.515 & 0.192 & 1.120 \\
\hline 9 & 87 & 0.010 & 0.292 & 0.288 & -2.559 & 2.359 & -0.153 & 1.033 \\
\hline 10 & 87 & 0.014 & 0.335 & 0.342 & -2.415 & 2.25 & 0.308 & 2.038 \\
\hline 11 & 87 & 0.044 & 0.979 & 1.036 & -2.741 & 2.656 & 1.098 & 5.016 \\
\hline 12 & 87 & 0.036 & 0.703 & 0.728 & -2.566 & 2.714 & 0.718 & 5.566 \\
\hline 13 & 87 & 0.031 & 0.512 & 0.577 & -2.736 & 2.814 & 2.356 & 16.800 \\
\hline 14 & 87 & 0.085 & 1.398 & 1.624 & -2.804 & 2.901 & 2.580 & 15.777 \\
\hline 15 & 87 & 0.117 & 1.746 & 2.085 & -2.976 & 2.853 & 2.668 & 16.099 \\
\hline 16 & 87 & 0.089 & 1.367 & 1.518 & -2.838 & 2.696 & 1.786 & 8.584 \\
\hline 17 & 87 & 0.106 & 1.670 & 1.793 & -2.486 & 2.669 & 1.048 & 4.907 \\
\hline 18 & 87 & 0.140 & 1.690 & 2.025 & -2.768 & 2.793 & 2.789 & 15.563 \\
\hline 19 & 87 & 0.148 & 1.578 & 1.935 & -2.753 & 2.567 & 3.344 & 17.974 \\
\hline 20 & 87 & 0.152 & 1.689 & 2.056 & -2.587 & 2.666 & 3.060 & 16.422 \\
\hline 21 & 87 & 0.109 & 1.357 & 1.53 & -2.656 & 2.547 & 2.059 & 9.584 \\
\hline 22 & 87 & 0.089 & 1.254 & 1.342 & -2.482 & 2.754 & 1.189 & 4.315 \\
\hline 23 & 87 & 0.130 & 1.735 & 1.837 & -2.639 & 2.635 & 0.808 & 2.349 \\
\hline 24 & 87 & 0.124 & 1.501 & 1.599 & -2.551 & 2.486 & 1.003 & 2.920 \\
\hline 25 & 87 & 0.161 & 1.732 & 1.934 & -2.801 & 2.63 & 1.614 & 6.448 \\
\hline 26 & 87 & 0.211 & 2.006 & 2.29 & -2.636 & 2.508 & 1.761 & 7.079 \\
\hline 27 & 87 & 0.364 & 2.234 & 3.031 & -2.914 & 2.949 & 4.066 & 22.522 \\
\hline 28 & 87 & 0.413 & 1.851 & 2.743 & -2.792 & 2.85 & 6.363 & 49.871 \\
\hline 29 & 87 & 0.425 & 1.780 & 2.679 & -2.666 & 2.7 & 6.859 & 56.352 \\
\hline 30 & 87 & 0.373 & 1.867 & 2.725 & -2.892 & 2.687 & 6.027 & 46.440 \\
\hline 31 & 87 & 0.255 & 1.598 & 2.008 & -2.912 & 2.648 & 3.760 & 23.568 \\
\hline 32 & 87 & 0.203 & 1.078 & 1.418 & -2.876 & 2.846 & 5.716 & 44.580 \\
\hline 33 & 87 & 0.211 & 0.954 & 1.274 & -2.841 & 2.609 & 6.345 & 51.760 \\
\hline 34 & 87 & 0.155 & 0.840 & 1.054 & -2.807 & 2.775 & 4.982 & 38.066 \\
\hline 35 & 87 & 0.166 & 0.772 & 0.997 & -2.638 & 2.688 & 5.757 & 46.431 \\
\hline 36 & 87 & 0.220 & 1.000 & 1.3 & -3.091 & 2.877 & 5.611 & 44.399 \\
\hline 37 & 87 & 0.272 & 1.229 & 1.661 & -2.861 & 2.712 & 6.014 & 47.760 \\
\hline 38 & 87 & 0.252 & 1.514 & 1.935 & -2.991 & 2.97 & 4.220 & 28.896 \\
\hline 39 & 87 & 0.282 & 1.729 & 2.245 & -2.751 & 2.686 & 4.136 & 27.962 \\
\hline 40 & 87 & 0.337 & 1.842 & 2.474 & -2.982 & 2.724 & 4.539 & 31.268 \\
\hline 41 & 87 & 0.374 & 1.945 & 2.706 & -2.596 & 2.848 & 4.971 & 36.013 \\
\hline 42 & 86 & 0.345 & 1.473 & 2.002 & -2.818 & 2.707 & 5.518 & 41.645 \\
\hline 43 & 86 & 0.338 & 1.484 & 1.976 & -2.82 & 2.763 & 5.065 & 36.029 \\
\hline 44 & 86 & 0.344 & 1.284 & 1.764 & -2.888 & 2.58 & 6.204 & 49.114 \\
\hline 45 & 86 & 0.402 & 1.100 & 1.547 & -2.577 & 2.698 & 7.274 & 62.522 \\
\hline 46 & 85 & 0.333 & 1.067 & 1.321 & -2.911 & 2.572 & 4.291 & 37.375 \\
\hline 47 & 85 & 0.397 & 1.492 & 1.851 & -3.016 & 2.664 & 3.643 & 23.407 \\
\hline 48 & 85 & 0.320 & 1.129 & 1.136 & -2.666 & 2.982 & 0.104 & 13.804 \\
\hline 49 & 85 & 0.278 & 0.977 & 1.048 & -3.003 & 2.921 & 1.347 & 14.872 \\
\hline 50 & 85 & 0.277 & 0.916 & 0.987 & -2.743 & 2.729 & 1.471 & 17.361 \\
\hline 51 & 85 & 0.260 & 0.889 & 0.954 & -2.806 & 3.187 & 1.397 & 17.202 \\
\hline 52 & 85 & 0.350 & 1.154 & 1.196 & -2.629 & 2.674 & 0.637 & 16.466 \\
\hline 53 & 85 & 0.362 & 1.297 & 1.331 & -2.708 & 2.905 & 0.425 & 14.558 \\
\hline 54 & 85 & 0.366 & 1.313 & 1.165 & -2.587 & 2.84 & -1.841 & 16.042 \\
\hline 55 & 84 & 0.277 & 0.891 & 0.735 & -2.683 & 3.122 & -3.316 & 24.924 \\
\hline 56 & 84 & 0.140 & 0.389 & 0.274 & -2.531 & 2.905 & -4.878 & 38.610 \\
\hline 57 & 84 & 0.205 & 0.633 & 0.509 & -2.978 & 2.931 & -3.793 & 29.151 \\
\hline 58 & 83 & 0.113 & 0.327 & 0.225 & -2.839 & 3.053 & -4.590 & 35.622 \\
\hline 59 & 82 & 0.043 & 0.120 & 0.022 & -2.81 & 3.091 & -5.210 & 40.325 \\
\hline 60 & 82 & 0.114 & 0.406 & 0.318 & -2.809 & 2.807 & -3.598 & 25.216 \\
\hline
\end{tabular}


Table A5

Summary Statistic for BHAR Using the Market Portfolio as a Benchmark

\begin{tabular}{|c|c|c|c|c|c|c|c|c|}
\hline Month & $\mathbf{N}$ & Mean & t-stat & Adj-SK-t & F1-1\%b & F1-99\%b & Skewness & Kurtosis \\
\hline 1 & 87 & 0.003 & 0.222 & 0.229 & -2.517 & 2.314 & 0.356 & 1.531 \\
\hline 2 & 87 & 0.010 & 0.731 & 0.773 & -2.443 & 2.509 & 1.129 & 3.344 \\
\hline 3 & 87 & 0.002 & 0.125 & 0.146 & -2.616 & 2.364 & 1.114 & 4.430 \\
\hline 4 & 87 & 0.015 & 0.735 & 0.786 & -2.471 & 2.687 & 1.356 & 5.424 \\
\hline 5 & 87 & 0.016 & 0.645 & 0.713 & -2.497 & 2.790 & 2.057 & 11.638 \\
\hline 6 & 87 & 0.015 & 0.561 & 0.637 & -2.871 & 2.758 & 2.615 & 14.408 \\
\hline 7 & 87 & 0.013 & 0.446 & 0.503 & -2.754 & 2.780 & 2.314 & 9.919 \\
\hline 8 & 87 & 0.028 & 0.891 & 0.952 & -2.875 & 2.266 & 1.332 & 3.516 \\
\hline 9 & 87 & 0.021 & 0.683 & 0.741 & -2.629 & 2.594 & 1.682 & 4.889 \\
\hline 10 & 87 & 0.014 & 0.395 & 0.439 & -2.530 & 2.634 & 1.883 & 5.973 \\
\hline 11 & 87 & 0.019 & 0.492 & 0.558 & -2.810 & 2.568 & 2.488 & 10.560 \\
\hline 12 & 87 & 0.025 & 0.633 & 0.701 & -2.758 & 2.546 & 2.128 & 9.543 \\
\hline 13 & 87 & 0.005 & 0.092 & 0.174 & -2.815 & 2.738 & 4.492 & 31.865 \\
\hline 14 & 87 & 0.034 & 0.608 & 0.739 & -2.768 & 2.741 & 4.198 & 28.362 \\
\hline 15 & 87 & 0.058 & 0.906 & 1.118 & -2.995 & 2.708 & 4.513 & 30.711 \\
\hline 16 & 87 & 0.043 & 0.704 & 0.843 & -2.721 & 3.068 & 3.898 & 22.625 \\
\hline 17 & 87 & 0.049 & 0.791 & 0.924 & -2.670 & 2.779 & 3.308 & 16.569 \\
\hline 18 & 87 & 0.085 & 0.979 & 1.234 & -3.060 & 2.775 & 4.886 & 31.881 \\
\hline 19 & 87 & 0.115 & 1.135 & 1.445 & -3.007 & 2.939 & 4.852 & 30.183 \\
\hline 20 & 87 & 0.140 & 1.476 & 1.916 & -2.753 & 3.025 & 4.597 & 27.909 \\
\hline 21 & 87 & 0.101 & 1.150 & 1.399 & -2.768 & 2.921 & 3.818 & 20.848 \\
\hline 22 & 87 & 0.065 & 0.787 & 0.909 & -2.637 & 2.921 & 3.053 & 14.250 \\
\hline 23 & 87 & 0.089 & 0.987 & 1.166 & -2.843 & 2.729 & 3.409 & 17.634 \\
\hline 24 & 87 & 0.074 & 0.828 & 0.923 & -2.825 & 2.816 & 2.246 & 7.192 \\
\hline 25 & 87 & 0.078 & 0.810 & 0.911 & -2.678 & 2.808 & 2.432 & 7.661 \\
\hline 26 & 87 & 0.105 & 1.012 & 1.157 & -2.781 & 2.857 & 2.665 & 9.128 \\
\hline 27 & 87 & 0.217 & 1.300 & 1.636 & -2.895 & 2.792 & 4.284 & 21.934 \\
\hline 28 & 87 & 0.260 & 1.150 & 1.555 & -2.925 & 2.766 & 6.230 & 45.791 \\
\hline 29 & 87 & 0.268 & 1.133 & 1.569 & -2.780 & 2.787 & 6.854 & 54.763 \\
\hline 30 & 87 & 0.206 & 1.023 & 1.344 & -3.168 & 2.850 & 5.815 & 41.726 \\
\hline 31 & 87 & 0.130 & 0.805 & 0.981 & -2.947 & 2.698 & 4.294 & 22.717 \\
\hline 32 & 87 & 0.147 & 0.793 & 1.033 & -2.902 & 2.798 & 5.933 & 43.666 \\
\hline 33 & 87 & 0.133 & 0.618 & 0.828 & -2.826 & 2.682 & 6.644 & 52.354 \\
\hline 34 & 87 & 0.059 & 0.345 & 0.469 & -2.903 & 2.650 & 5.588 & 40.718 \\
\hline 35 & 87 & 0.065 & 0.332 & 0.478 & -2.711 & 2.735 & 6.706 & 54.465 \\
\hline 36 & 87 & 0.078 & 0.378 & 0.523 & -2.836 & 2.740 & 6.293 & 49.386 \\
\hline 37 & 87 & 0.098 & 0.454 & 0.609 & -2.799 & 2.663 & 6.110 & 46.626 \\
\hline 38 & 87 & 0.024 & 0.149 & 0.232 & -3.212 & 2.988 & 4.405 & 27.646 \\
\hline 39 & 87 & 0.011 & 0.065 & 0.140 & -2.879 & 2.698 & 4.127 & 24.846 \\
\hline 40 & 87 & 0.027 & 0.147 & 0.232 & -2.537 & 2.855 & 4.570 & 28.741 \\
\hline 41 & 87 & 0.071 & 0.378 & 0.493 & -2.844 & 2.991 & 5.010 & 34.272 \\
\hline 42 & 86 & 0.097 & 0.426 & 0.562 & -2.773 & 2.782 & 5.535 & 39.715 \\
\hline 43 & 86 & 0.101 & 0.460 & 0.588 & -2.746 & 2.840 & 4.987 & 33.265 \\
\hline 44 & 86 & 0.172 & 0.666 & 0.876 & -2.685 & 2.611 & 6.199 & 47.755 \\
\hline 45 & 86 & 0.261 & 0.752 & 1.044 & -2.456 & 2.554 & 7.640 & 65.559 \\
\hline 46 & 85 & 0.184 & 0.658 & 0.861 & -2.742 & 2.710 & 6.005 & 45.316 \\
\hline 47 & 85 & 0.206 & 0.816 & 0.989 & -2.946 & 2.786 & 4.117 & 22.589 \\
\hline 48 & 85 & 0.180 & 0.760 & 0.874 & -2.579 & 2.500 & 2.923 & 10.436 \\
\hline 49 & 85 & 0.146 & 0.591 & 0.695 & -2.894 & 2.547 & 3.414 & 15.167 \\
\hline 50 & 85 & 0.193 & 0.752 & 0.892 & -2.866 & 2.908 & 3.635 & 18.299 \\
\hline 51 & 85 & 0.115 & 0.466 & 0.555 & -2.776 & 2.536 & 3.447 & 17.085 \\
\hline 52 & 85 & 0.157 & 0.643 & 0.755 & -3.030 & 2.682 & 3.383 & 16.504 \\
\hline 53 & 85 & 0.153 & 0.669 & 0.769 & -3.107 & 2.840 & 2.916 & 11.929 \\
\hline 54 & 85 & 0.128 & 0.595 & 0.652 & -2.463 & 2.404 & 1.851 & 3.273 \\
\hline 55 & 84 & 0.144 & 0.679 & 0.737 & -2.367 & 2.394 & 1.682 & 2.459 \\
\hline 56 & 84 & 0.142 & 0.683 & 0.747 & -2.523 & 2.402 & 1.845 & 3.566 \\
\hline 57 & 84 & 0.165 & 0.799 & 0.873 & -2.478 & 2.419 & 1.777 & 3.349 \\
\hline 58 & 83 & 0.051 & 0.259 & 0.293 & -2.668 & 2.419 & 1.639 & 2.767 \\
\hline 59 & 82 & 0.041 & 0.206 & 0.239 & -2.274 & 2.266 & 1.639 & 2.745 \\
\hline 60 & 82 & -0.027 & -0.143 & -0.117 & -2.769 & 2.307 & 1.361 & 1.634 \\
\hline
\end{tabular}

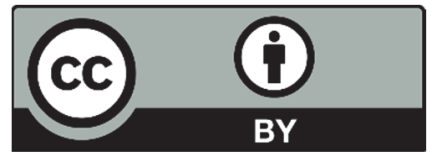

(C) 2020 by the authors; licensee Growing Science, Canada. This is an open access article distributed under the terms and conditions of the Creative Commons Attribution (CC-BY) license (http://creativecommons.org/licenses/by/4.0/). 